\title{
Optimal design of fibre reinforced tubular structures
}

\author{
H. Martikka \& E. Taitokari \\ Department of Mechanical Engineering, \\ Lappeenranta University of Technology, Lappeenranta, Finland
}

\begin{abstract}
The main purpose of this study is to present results of the design and damage analysis of industrial vessel shell microstructures made of fibre reinforced plastic laminates and subject to mechanical and aggressive chemical loads due to sulphuric and hydrochloric acids and high temperatures. Methods to obtain optimal performance microstructure are use of balanced and symmetric laminate layering with optimal fibre strengthening directions and volume fractions. Optimal selection of chemically resistant fibres and matrix is essential for endurance. Use of thick enough walls is cost-effective for vessel bottoms. Two vessel winding manufacturing technologies are compared for optimal selection. Keywords: composite materials and structures, optimal design, stress corrosion cracking.
\end{abstract}

\section{Introduction}

Composites used for structural engineering are commonly formed from five commonest material groups, metals, ceramics, glasses, elastomers and polymers. Design rules and codes are based continuum models. Another trend is to use more microscopic modelling. Useful information of composite design is presented by Agarwal and Broutman [1] and Barbero [2]. Chemical resistances are studied by Aveston and Sillwood [3] and, Kawada and Srivastava [4]. In aggressive enough loadings all material alternatives and combinations suffer accumulation of damage. Typical damage events are stress corrosion wearing of outer surface, fracture of fibres and degradation of matrix. The main purpose of this study is to present results of design and damage study analysis of industrial vessel walls. 


\section{Goals, materials and methods}

\subsection{General goals of designing thin shelled structures for process industry}

In metallurgical chemical industry concentrated sulphuric and hydrochloric acids are processed at about boiling temperature in thin shelled large vessels. The focus is now on shells made inorganic composites, Figure 1.

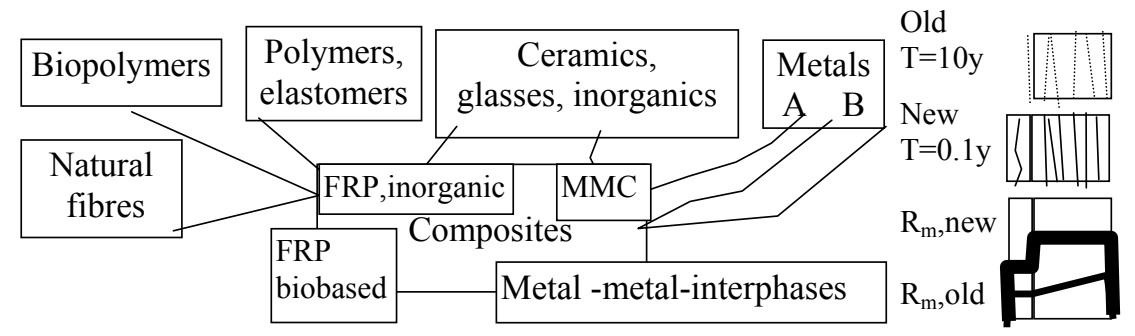

a)

b)

Figure 1: a) Composite structure relationships. b) Environmental attack on a two layered composite causing wear and decrease of strength $R_{\mathrm{m}}$.

\subsection{Materials and loads}

The principle of designing composite walls is to use functional property gradients. Chemical resistance is needed close to inner wall. Load bearing capacity is obtained by making the walls strong and thick enough.

The fibre materials are typically glass fibres. Now elastic modulus is $E_{\mathrm{f}}=$ $70000 \mathrm{MPa}$, fracture strain $\varepsilon_{\mathrm{fu}}=0.012$. Options are normal low cost E-glass and special chemically resistant glass. Matrix modulus is typically $E_{\mathrm{m}}=3400$, tensile strength $83 \mathrm{MPa}$ and shear strength of same magnitude.

Load is $20 \%$ sulphuric and hydrochloric acid at $104^{\circ} \mathrm{C}$.

\section{Background theory}

\subsection{Micromechanical properties of plane strain orthotropic lamina layers}

In principal LT material directions the relation between principal strains and principal stresses is given by the principal material direction stiffness matrix $\mathbf{Q}$. It is the Hooke's law

$$
\left[\begin{array}{c}
\sigma_{L} \\
\sigma_{\mathrm{T}} \\
\tau_{\mathrm{LT}}
\end{array}\right]=\left[\begin{array}{ccc}
Q_{11} & Q_{12} & 0 \\
Q_{12} & Q_{22} & 0 \\
0 & 0 & Q_{66}
\end{array}\right]\left[\begin{array}{c}
\varepsilon_{L} \\
\varepsilon_{\mathrm{T}} \\
\gamma_{\mathrm{LT}}
\end{array}\right]
$$

\subsubsection{Stresses in global and principal strength directions}

Each lamina gets its input loads from the global strain distribution. Use of the direction transformation matrix gives the components in principal directions. 


$$
\left[\begin{array}{c}
\sigma_{L} \\
\sigma_{\mathrm{T}} \\
\tau_{\mathrm{LT}}
\end{array}\right]_{k}=\left[\begin{array}{ccc}
c^{2} & s^{2} & 2 s c \\
s^{2} & c^{2} & -2 s c \\
-s c & s c & c^{2}-s^{2}
\end{array}\right]_{k}\left[\begin{array}{c}
\sigma_{\mathrm{x}} \\
\sigma_{\mathrm{y}} \\
\tau_{\mathrm{xy}}
\end{array}\right]_{\mathrm{k}} \quad, \quad\left\{\sigma_{\mathrm{L}}\right\}_{\mathrm{k}}=[\mathbf{T}]\left\{\sigma_{\mathbf{x}}\right\}_{\mathrm{k}}
$$

Transformation of stiffness matrix components from principal to global xy coordinates gives

$$
\begin{aligned}
& \bar{Q}_{11} \rightarrow \bar{Q}_{11, k}=Q_{11} c^{4}+Q_{22} s^{4}+2\left(Q_{12}+2 Q_{66}\right) s^{2} c^{2} \\
& \bar{Q}_{22} \rightarrow \bar{Q}_{22, k}=Q_{11} s^{4}+Q_{22} c^{4}+2\left(Q_{12}+2 Q_{66}\right) s^{2} c^{2} \\
& \bar{Q}_{12} \rightarrow \bar{Q}_{12, k}=\left(Q_{11}+Q_{22}-4 Q_{66}\right) s^{2} c^{2}+Q_{12}\left(c^{4}+s^{4}\right) \\
& \bar{Q}_{66} \rightarrow \bar{Q}_{66, k}=\left(Q_{11}+Q_{22}-2 Q_{12}-2 Q_{66}\right) s^{2} c^{2}+Q_{66}\left(c^{4}+s^{4}\right) \\
& \bar{Q}_{16} \rightarrow \bar{Q}_{16, k}=\left(Q_{11}-Q_{12}-2 Q_{66}\right) s c^{3}-\left(Q_{22}-Q_{12}-2 Q_{66}\right) s^{3} c \\
& \bar{Q}_{26} \rightarrow \bar{Q}_{21, k}=\left(Q_{11}-Q_{12}-2 Q_{66}\right) s^{3} c-\left(Q_{22}-Q_{12}-2 Q_{66}\right) s c^{3}
\end{aligned}
$$

The global midplane strain induces global stresses at layer $\mathrm{k}$ with angle $\theta$ to $\mathrm{x}$ axis

$$
\left[\begin{array}{c}
\sigma_{\mathrm{x}} \\
\sigma_{\mathrm{y}} \\
\tau_{\mathrm{xy}}
\end{array}\right]_{k}=\left[\begin{array}{lll}
\bar{Q}_{11} & \bar{Q}_{12} & \bar{Q}_{16} \\
\bar{Q}_{12} & \bar{Q}_{22} & \bar{Q}_{26} \\
\bar{Q}_{16} & \bar{Q}_{26} & \bar{Q}_{66}
\end{array}\right]_{\mathrm{k}}\left[\begin{array}{c}
\varepsilon_{\mathrm{x}}{ }^{0}{ }^{0} \\
\varepsilon_{\mathrm{y}}{ }^{0}{ }_{\mathrm{xy}}{ }^{0}
\end{array}\right], \quad\left\{\sigma_{\mathrm{x}}\right\}_{\mathrm{k}}=[\overline{\mathbf{Q}}]\left\{\varepsilon_{\mathbf{x}}{ }^{0}\right\}
$$

\subsubsection{Force and moment resultants of all layers}

Force resultants are needed. They are obtained by integrating over the thickness

$$
\begin{aligned}
& {\left[\begin{array}{c}
N_{x} \\
N_{y} \\
N_{x y}
\end{array}\right]=\sum_{k=1}^{k=n} \int_{h_{\mathrm{k}-1}}^{h_{\mathrm{k}}}\left[\begin{array}{c}
\sigma_{x} \\
\sigma_{y} \\
\tau_{x y}
\end{array}\right]_{\mathrm{k}} d z=\sum_{k=1}^{k=n} \int_{h_{\mathrm{k}-1}}^{h_{\mathrm{k}}} \sigma_{\mathrm{k}} d z} \\
& \sigma=\bar{Q} \varepsilon=\bar{Q}\left(\varepsilon_{0}+z \kappa\right)=\bar{Q} \varepsilon_{0}+z \bar{Q} \kappa
\end{aligned}
$$

In component vector form the force resultant vector is

$$
\left[\begin{array}{c}
N_{x} \\
N_{y} \\
N_{x y}
\end{array}\right]=\left[A_{\mathrm{ij}}\right] \cdot\left[\begin{array}{c}
\varepsilon_{\mathrm{x}}{ }^{0} \\
\varepsilon_{\mathrm{y}}{ }^{0} \\
\gamma_{\mathrm{xy}}{ }^{0}
\end{array}\right]+\left[B_{\mathrm{ij}}\right]\left[\begin{array}{c}
\kappa_{\mathrm{x}} \\
\kappa_{\mathrm{y}} \\
\kappa_{\mathrm{xy}}
\end{array}\right]
$$

where the $\mathbf{A}$ and $\mathbf{B}$ matrices are 


$$
\left[A_{\mathrm{ij}}\right]=\sum_{k=1}^{k=n}\left\langle\bar{Q}_{\mathrm{ij}}\right\rangle_{\mathrm{k}} \bullet\left(h_{\mathrm{k}}-h_{\mathrm{k}-1}\right) \quad, \quad\left[B_{\mathrm{ij}}\right]=\frac{1}{2} \sum_{k=1}^{k=n}\left\langle\bar{Q}_{\mathrm{ij}}\right\rangle_{\mathrm{k}} \bullet\left(h_{\mathrm{k}}{ }^{2}-h_{\mathrm{k}-1}{ }^{2}\right)
$$

Use of these is illustrated in the case study model, shown in Figure 2.
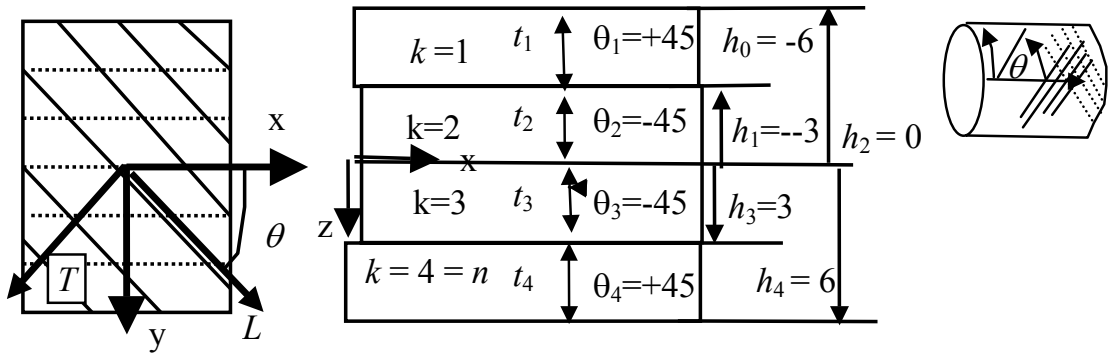

Figure 2: $\quad$ Principle of a symmetric and balanced composite $+45 /-45 /-45 /+45$.

The ABD matrix relates the midplane strains and plate curvatures to resultant force vector $\mathbf{N}$ and moment vector $\mathbf{M}$. The ABD matrices are extensional stiffness matrix $\mathbf{A}$, coupling stiffness matrix $\mathbf{B}$ and bending stiffness matrix $\mathbf{D}$.

$$
\left[\begin{array}{l}
\mathbf{N} \\
\mathbf{M}
\end{array}\right]=\left[\begin{array}{ll}
\mathbf{A} & \mathbf{B} \\
\mathbf{B} & \mathbf{D}
\end{array}\right]\left[\begin{array}{l}
\varepsilon^{0} \\
\kappa
\end{array}\right] \Rightarrow\left[\begin{array}{ll}
\mathbf{A} & \mathbf{B} \\
\mathbf{B} & \mathbf{D}
\end{array}\right]\left[\begin{array}{c}
\varepsilon^{0} \\
0
\end{array}\right] \rightarrow\left[\begin{array}{l}
\mathbf{A} \varepsilon^{0} \\
\mathbf{B} \varepsilon^{0}
\end{array}\right]
$$

In formulating the design goals and constraints the symmetry condition is the stiffest one. These rules can be utilised to obtain simple and well functioning microstructures.

\subsubsection{Symmetric laminate structure as one optimisation goal}

The useful result of using symmetry goal is that the $\mathbf{B}$ matrix is made zero. Using the case study data

$$
[\bar{Q}]_{\mathrm{k}=1,+45 \mathrm{deg}}=[\bar{Q}]_{\mathrm{k}=4,+45 \mathrm{deg}} \quad, \quad[\bar{Q}]_{\mathrm{k}=2,-45 \mathrm{deg}}=[\bar{Q}]_{\mathrm{k}=3,-45 \mathrm{deg}}
$$

Gives for the B matrix

$$
\left[B_{\mathrm{ij}}\right]=\frac{1}{2}\left([\bar{Q}]_{1}\left(t^{2}-4 t^{2}\right)+[\bar{Q}]_{2}\left(0^{2}-t^{2}\right)+[\bar{Q}]_{2}\left(t^{2}-0^{2}\right)+[\bar{Q}]_{1}\left(4 t^{2}-t^{2}\right)\right)=0
$$

The simplified result form is

$$
\left[\begin{array}{l}
\mathbf{N} \\
\mathbf{M}
\end{array}\right]=\left[\begin{array}{ll}
\mathbf{A} & 0 \\
0 & \mathbf{D}
\end{array}\right]\left[\begin{array}{l}
\varepsilon^{0} \\
\kappa
\end{array}\right] \Rightarrow\left[\begin{array}{cc}
\mathbf{A} & 0 \\
0 & \mathbf{D}
\end{array}\right]\left[\begin{array}{c}
\varepsilon^{0} \\
0
\end{array}\right] \rightarrow\left[\begin{array}{c}
\mathbf{A} \varepsilon^{0} \\
0
\end{array}\right]
$$




\subsubsection{Balanced laminate structure as one optimisation goal}

The next optimisation goal is to simplify the A matrix as much as possible. This goal is reached by adjusting the transformed stiffness components.

If for every layer there is another almost identical layer but with opposite orientation somewhere in the laminate, the sign of sine function is changed. This means that $\mathrm{Q}_{16}$ and $\mathrm{Q}_{26}$ are zero meaning that $\mathrm{A}_{16}, \mathrm{~A}_{26}$ are zero. For instance

$$
\begin{aligned}
& \bar{Q}_{16} \rightarrow+\theta \rightarrow \sin \theta=+s=\left(Q_{11}-Q_{12}-2 Q_{66}\right) s c^{3}-\left(Q_{22}-Q_{12}-2 Q_{66}\right) s^{3} c \\
& \bar{Q}_{16}{ }^{\prime} \rightarrow-\theta \rightarrow \sin (-\theta)=-s=-\left(Q_{11}-Q_{12}-2 Q_{66}\right) s c^{3}+\left(Q_{22}-Q_{12}-2 Q_{66}\right) s^{3} c=-\bar{Q}_{16}
\end{aligned}
$$

Using this result in A matrix and setting laminate layers constant $\Delta h=t$

$$
\left[A_{16}\right]=\ldots \bar{Q}_{16} \bullet t+\bar{Q}_{16} \bullet t=t \bullet\left(\bar{Q}_{16}-\bar{Q}_{16}\right)=0
$$

Using this one obtains for the A matrix

$$
\begin{gathered}
{\left[A_{\mathrm{ij}}\right]=t \sum_{k=1}^{4}\left\langle\bar{Q}_{\mathrm{ij}}\right\rangle_{\mathrm{k}}=t\left(\left(\bar{Q}_{\mathrm{ij}}\right)_{1}+\left(\bar{Q}_{\mathrm{ij}}\right)_{2}+\left(\bar{Q}_{\mathrm{ij}}\right)_{3}+\left(\bar{Q}_{\mathrm{ij}}\right)_{4}\right), \quad T=\Sigma t} \\
{\left[\begin{array}{c}
N_{\mathrm{x}} \\
N_{\mathrm{y}} \\
N_{\mathrm{xy}}
\end{array}\right]=\left[\begin{array}{lll}
A_{11} & A_{12} & A_{16} \\
A_{12} & A_{22} & A_{26} \\
A_{16} & A_{26} & A_{66}
\end{array}\right]\left[\begin{array}{c}
\varepsilon_{\mathrm{x}}{ }^{0} \\
\varepsilon_{\mathrm{y}}{ }^{0} \\
\gamma_{\mathrm{xy}}{ }^{0}
\end{array}\right] \Rightarrow\left[\begin{array}{ccc}
A_{11} & A_{12} & 0 \\
A_{12} & A_{22} & 0 \\
0 & 0 & A_{66}
\end{array}\right]\left[\begin{array}{c}
\varepsilon_{\mathrm{x}}{ }^{0} \\
\varepsilon_{\mathrm{y}}{ }^{0} \\
\gamma_{\mathrm{xy}}{ }^{0}
\end{array}\right]}
\end{gathered}
$$

Force resultant depends on strains caused by global load stresses

$$
\begin{aligned}
& {\left[\begin{array}{l}
N_{\mathrm{x}} \\
N_{\mathrm{y}}
\end{array}\right]=\left[\begin{array}{ll}
A_{11} & A_{12} \\
A_{12} & A_{22}
\end{array}\right]\left[\begin{array}{l}
\varepsilon_{\mathrm{x}}{ }^{0} \\
\varepsilon_{\mathrm{y}}{ }^{0}
\end{array}\right],\left[\begin{array}{l}
N_{\mathrm{x}} \\
N_{\mathrm{y}}
\end{array}\right]=\Sigma t\left[\begin{array}{l}
\sigma_{\mathrm{x}} \\
\sigma_{\mathrm{y}}
\end{array}\right]=\Sigma t \frac{p r}{\Sigma t}\left[\begin{array}{c}
1 \\
0.5
\end{array}\right]=p r\left[\begin{array}{c}
1 \\
0.5
\end{array}\right]} \\
& N_{\mathrm{xy}}=A_{66} \gamma_{\mathrm{xy}}{ }^{0}
\end{aligned}
$$

The globally directed stresses acting on or within lamina $\mathrm{k}$ are

$$
\left[\begin{array}{c}
\sigma_{\mathrm{x}, \mathrm{k}} \\
\sigma_{\mathrm{y}, \mathrm{k}}
\end{array}\right]=\left[\begin{array}{ll}
\bar{Q}_{11} & \bar{Q}_{12} \\
\bar{Q}_{12} & \bar{Q}_{22}
\end{array}\right]_{k}\left[\begin{array}{c}
\varepsilon_{\mathrm{x}}{ }^{0} \\
\varepsilon_{\mathrm{y}}{ }^{0}
\end{array}\right]
$$

From this equation the midplane strains can be solved

$$
\begin{aligned}
& {\left[\begin{array}{l}
\varepsilon_{\mathrm{x}}{ }^{0} \\
\varepsilon_{\mathrm{y}}{ }^{0}
\end{array}\right]=\left[\begin{array}{ll}
a_{11} & a_{12} \\
a_{12} & a_{22}
\end{array}\right]\left[\begin{array}{l}
N_{\mathrm{x}} \\
N_{\mathrm{y}}
\end{array}\right]=\frac{1}{\operatorname{det} A}\left[\begin{array}{cc}
A_{22} & -A_{12} \\
-A_{12} & A_{11}
\end{array}\right]\left[\begin{array}{c}
N_{\mathrm{x}} \\
N_{\mathrm{y}}
\end{array}\right]} \\
& a_{66}=\frac{1}{A_{66}}, \operatorname{det} A=A_{11} A_{22}-A_{12}{ }^{2}
\end{aligned}
$$

whence the globally directed stresses acting on lamina depend on pressure 


$$
\left[\begin{array}{c}
\sigma_{\mathrm{x}, \mathrm{k}} \\
\sigma_{\mathrm{y}, \mathrm{k}}
\end{array}\right]=\left[\begin{array}{ll}
\bar{Q}_{11} & \bar{Q}_{12} \\
\bar{Q}_{12} & \bar{Q}_{22}
\end{array}\right]_{k}\left[\begin{array}{ll}
a_{11} & a_{12} \\
a_{12} & a_{22}
\end{array}\right]\left[\begin{array}{c}
1 \\
0.5
\end{array}\right] p r
$$

\subsubsection{Stresses in laminate layers}

Using the xy global stress in layer $\mathrm{k}$ the stresses in principal directions LT of a layer $\mathrm{k}$ can be calculated. These are needed in stress based failure criteria

$$
\left[\begin{array}{c}
\sigma_{\mathrm{L}, \mathrm{k}} \\
\sigma_{\mathrm{T}, \mathrm{k}} \\
\tau_{\mathrm{LT}, \mathrm{k}}
\end{array}\right]=\left[\begin{array}{ccc}
c^{2} & s^{2} & 2 s c \\
s^{2} & c^{2} & -2 s c \\
-s c & s c & c^{2}-s^{2}
\end{array}\right]_{k}\left[\begin{array}{c}
\sigma_{\mathrm{x}, \mathrm{k}} \\
\sigma_{\mathrm{y}, \mathrm{k}} \\
\tau_{\mathrm{xy}}=0
\end{array}\right]
$$

\subsection{Environmental interaction effects}

The degradation of composite materials may result from several factors [1]

1) Loss of strength of reinforcing fibres by stress-corrosion

2) Loss of adhesion and interfacial bond strength degradation

3) Chemical degradation of the matrix material

4) Dependence of the matrix modulus and strength on time and temperature.

One present observation is that rise of temperature from $20 \mathrm{C} \Rightarrow 100 \mathrm{C}$ lowers the modulus to half $3400 \Rightarrow 1700 \mathrm{MPa}$

5) Accelerated degradation by temperature and chemical environment.

\subsubsection{Failure mechanisms in fibre reinforced structures}

Some failure mechanisms in fibre reinforced structures are shown in Figure 3.
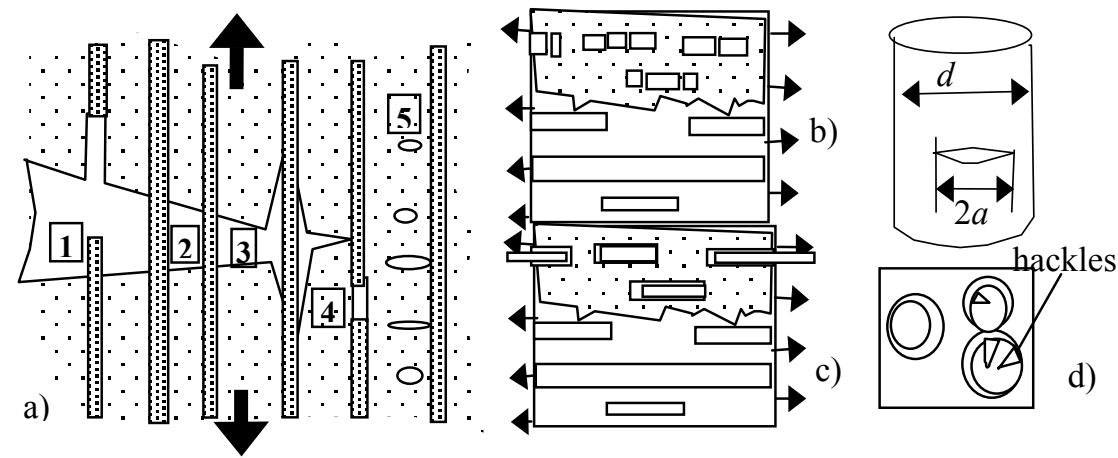

Figure 3: a) Crack growth in fibre reinforced material by various mechanisms, 1. Fibre pull-out. 2. Fibre bridging, 3. Fibre/matrix debonding, 4. Fibre failure, 5. Matrix cracking. b) In E/VE composite the solution gets into contact with E-glass to corrode fibres. In E-glass there are $\mathrm{Al}_{2} \mathrm{O}_{3}$ and $\mathrm{Fe}_{2} \mathrm{O}_{3}$ compounds which corrode forming hydroxides. c) In $\mathrm{C} / \mathrm{VE}$ glass water diffuses into matrix swelling it. Acid corrodes interfaces but less fibres. The result is that fibres are loosened and pull-out takes place. d) Fibre cross-section fracture models. 


\subsubsection{Condition of chemical endurance}

The industrial goal is to ensure that the wall does not leak and burst. Both the strength and the load bearing effective wall thickness $T$ are decreased by the acid gas and liquid. Margin of safety goal is that stress should be less than strength.

Dominant stress is the hoop stress. It increases when the wall corrodes. The strength decreases also and the factor safety $N$ should be large enough

$$
\begin{gathered}
\sigma_{\mathrm{x}}=p \frac{r}{T} \leq \frac{1}{N} R_{\mathrm{m}}=\frac{1}{N} R_{\mathrm{m} 0} \frac{1}{t^{\mathrm{p}}} \\
R_{\mathrm{m}}=10^{a} t^{b} \approx 100 \bullet t^{-0.163}, R_{\mathrm{m}}[M P a], t[\text { years }]
\end{gathered}
$$

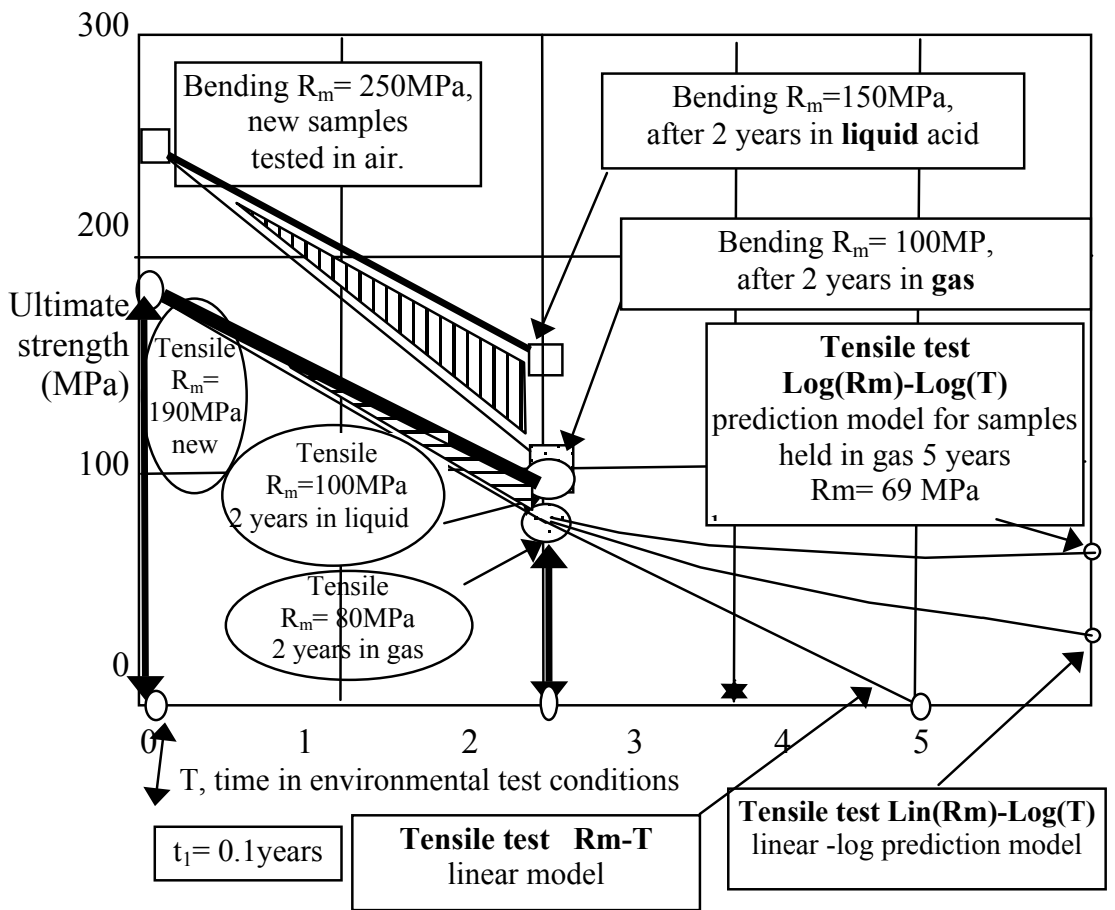

Figure 4: Experimental testing of E-glass vinylester $25 \mathrm{~mm}$ thick laminates at Sulphuric-hydrochloric $20 \%$ acid at $104{ }^{\circ} \mathrm{C}$ and in gas above it. Average stress was zero.

\subsection{Model of stress corrosion aided crack growth of fibres}

Aveston and Sillwood [3] have studied conditions for crack growth in E-glass unidirectional polyester in $1 \mathrm{~N} \mathrm{H}_{2} \mathrm{SO}_{4}$. They made several tests a1) static load, a2) static load with pre-soak for $1.8 \cdot 10^{6} \mathrm{sec}$, a3) Fatigue $0.1 \mathrm{~Hz}$ square wave. All points were close each other allowing a single model for crack growth rate to be used nearly independent of the time dependence of load stress as 


$$
\begin{aligned}
& V=\frac{d a}{d t}=A K_{\mathrm{I}}^{n}=9.55 \cdot 10^{-11} \cdot K_{\mathrm{I}}^{3} \quad \text { units: } V\left[\frac{m}{s}\right], \quad t[\mathrm{sec}], \quad \sigma[\mathrm{MPa}] \\
& K_{\mathrm{I}}=\sigma_{a} Y^{\prime} a^{1 / 2} \quad, \quad n \approx 3 \quad, \quad Y^{\prime}=Y \pi^{\frac{1}{2}}
\end{aligned}
$$

$\sigma_{\mathrm{a}}$ is applied stress, static or dynamic, $a$ is crack length at time $t, Y$ is a geometrical factor for crack. For a crack of length $2 a$ in a plate, $Y=1, Y^{\prime}=\pi^{1 / 2}$

Since the life of fibres is decisive for the whole composite, the fibre life can be regarded as the life time of the composite under full loading. Initial crack size is $a_{\mathrm{i}}$ and final $a_{\mathrm{IC}}$. Stress corrosion life is from initial to final crack size

$$
d t=\frac{d a}{A K_{\mathrm{I}}^{\mathrm{n}}}=\frac{d a}{A\left(\sigma_{a} Y^{\prime} a^{1 / 2}\right)^{\mathrm{n}}} \rightarrow \int_{0}^{t_{\mathrm{c}}} d t=t_{C}=\frac{1}{A Y^{\mathrm{n}} \sigma_{a}{ }^{\mathrm{n}}} \cdot \frac{1}{1-1 / 2 n}\left[a^{\frac{1}{2}(2-n)}\right]_{a i}^{a_{\mathrm{C}}}
$$

For short time testing, the applied stress is raised up to tensile strength while the crack starts at initial size. Stress intensities at initial and final crack sizes are

$$
K_{\mathrm{Ii}}=\sigma_{\mathrm{a}} Y^{\prime} a_{\mathrm{i}}^{1 / 2}, K_{\mathrm{IC}}=\sigma_{\mathrm{a}} Y^{\prime} a_{\mathrm{C}}^{1 / 2} \Rightarrow K_{\mathrm{IC}}=\sigma_{\max } Y^{\prime} a_{\mathrm{i}}^{1 / 2}, \sigma_{\max }=R_{\mathrm{m}}
$$

\section{Analytical optimisation}

This is based on the previous theory.

\subsection{Logic of finding optimal structure}

1. For Itt $=1$ to 3, $T(\mathrm{iItt}): \mathrm{T}(1)=.01, \mathrm{~T}(2)=.022, \mathrm{~T}(3)=.04$, wall thickness

2. For Ivf $=1$ to $2, V_{\mathrm{f}}(\mathrm{IVf}): V_{\mathrm{f}}(1)=0.14, V_{\mathrm{f}}(2)=0.46$, volume fraction

3. For Iss $=1$ to 2, $s$ (Iss) $: s=5000,20,1$, aspect ratio choices

Table 1: $\quad$ Material and model data.

\begin{tabular}{|l|l|l|}
\hline$E_{\mathrm{f}}=70000$ & $v_{\mathrm{f}}=0.22$ & $G_{\mathrm{f}}=\frac{E_{\mathrm{f}}}{2\left(1+v_{\mathrm{f}}\right)}$ \\
\hline$E_{\mathrm{m}}=3400$ & $v_{\mathrm{m}}=0.38$ & $G_{\mathrm{m}}=\frac{E_{\mathrm{m}}}{2\left(1+v_{\mathrm{m}}\right)}$ \\
\hline$s=\frac{2 L}{d}, e=\frac{E_{\mathrm{f}}}{E_{\mathrm{m}}}$ & $\varepsilon_{\mathrm{fu}}(\mathrm{Im})=0.012$ & $v=\frac{G_{\mathrm{f}}}{G_{\mathrm{m}}}, z=1$ \\
\hline$\eta_{\mathrm{L}}=\frac{e-1}{e+2 s}$ & $\eta_{\mathrm{T}}=\frac{e-1}{e+2}$ & $\eta_{\mathrm{G}}=\frac{v-1}{v+z}$ \\
\hline
\end{tabular}

Goal is to calculate elements for the principal LT matrix $\mathbf{Q}$

$$
\begin{gathered}
E_{\mathrm{L}}=u E_{\mathrm{m}} \quad, u=\frac{1+2 s \eta_{\mathrm{L}} V_{\mathrm{f}}}{1-\eta_{\mathrm{L}} V_{\mathrm{f}}} \quad, E_{\mathrm{T}}=w E_{\mathrm{m}} \quad, w=\frac{1+2 \eta_{\mathrm{T}} V_{\mathrm{f}}}{1-\eta_{\mathrm{T}} V_{\mathrm{f}}} \\
G_{\mathrm{LT}}=g G_{\mathrm{m}} \quad, g=\frac{1+\eta_{\mathrm{G}} V_{\mathrm{f}}}{1-\eta_{\mathrm{G}} V_{\mathrm{f}}} \quad, v_{\mathrm{LT}}=v_{\mathrm{f}} V_{\mathrm{f}}+v_{\mathrm{m}} V_{\mathrm{m}} \quad, v_{\mathrm{TL}}=v_{\mathrm{LT}} \frac{E_{\mathrm{T}}}{E_{\mathrm{L}}}
\end{gathered}
$$


These models are input to principal LT stiffness matrix of orthotropic lamina

$$
\left[\begin{array}{c}
\sigma_{11} \\
\sigma_{22} \\
\tau_{12}
\end{array}\right]=\left[\begin{array}{ccc}
\frac{E_{\mathrm{L}}}{1-v_{\mathrm{LT}} v_{\mathrm{TL}}} & \frac{v_{\mathrm{LT}} E_{\mathrm{L}}}{1-v_{\mathrm{LT}} v_{\mathrm{TL}}} & 0 \\
\frac{v_{\mathrm{LT}} E_{\mathrm{L}}}{1-v_{\mathrm{LT}} v_{\mathrm{TL}}} & \frac{E_{\mathrm{T}}}{1-v_{\mathrm{LT}} v_{\mathrm{TL}}} & 0 \\
0 & 0 & G_{12}
\end{array}\right]\left[\begin{array}{c}
\varepsilon_{11} \\
\varepsilon_{22} \\
\gamma_{12}
\end{array}\right], \frac{v_{21}}{E_{2}}=\frac{v_{12}}{E_{1}}
$$

The $\mathbf{Q}$ matrix is in Hooke's law

$$
\left[\begin{array}{c}
\sigma_{L} \\
\sigma_{\mathrm{T}} \\
\tau_{\mathrm{LT}}
\end{array}\right]=\left[\begin{array}{ccc}
Q_{11} & Q_{12} & 0 \\
Q_{12} & Q_{22} & 0 \\
0 & 0 & Q_{66}
\end{array}\right]\left[\begin{array}{c}
\varepsilon_{L} \\
\varepsilon_{\mathrm{T}} \\
\gamma_{\mathrm{LT}}
\end{array}\right]
$$

4. for Ith $=1$ to 3, Angle $\theta($ Ith $)$, is varied

$$
\theta(1)=20, \theta(2)=40, \theta(3)=60 \ldots
$$

Next the transformed $\overline{\mathbf{Q}}_{\mathrm{k}}$ for layer $\mathrm{k}$ are calculated. The two optimising conditions of symmetry and balancing have been applied

For $\boldsymbol{k}^{\prime}=1$ to 4 , calculation of global stresses in lamina $k^{\prime}$

$$
\begin{gathered}
s=\sin \left(\theta_{\mathrm{k}}\right) \quad, \quad c=\cos \left(\theta_{\mathrm{k}}\right) \\
\left\{\sigma_{\mathrm{x}}\right\}_{\mathrm{k}}=[\overline{\mathbf{Q}}]\left\{\varepsilon_{\mathbf{x}}{ }^{0}\right\}
\end{gathered}
$$

Next $k^{\prime}$

\section{For $k=1$ to 4 loop for calculating lamina $k$ stresses and strengths}

Calculate A matrix

$$
\left[A_{\mathrm{ij}}\right]=t \sum_{k=1}^{4}\left\langle\bar{Q}_{\mathrm{ij}}\right\rangle_{\mathrm{k}}=t\left(\left(\bar{Q}_{\mathrm{ij}}\right)_{1}+\left(\bar{Q}_{\mathrm{ij}}\right)_{2}+\left(\bar{Q}_{\mathrm{ij}}\right)_{3}+\left(\bar{Q}_{\mathrm{ij}}\right)_{4}\right)
$$

Calculate inverse $\mathrm{A}=\mathbf{A}^{-1}=\mathbf{a}$

Calculate globally directed stresses in lamina layer $\mathrm{k}$

$$
\left[\begin{array}{c}
\sigma_{\mathrm{x}, \mathrm{k}} \\
\sigma_{\mathrm{y}, \mathrm{k}}
\end{array}\right]=\left[\begin{array}{ll}
\bar{Q}_{11} & \bar{Q}_{12} \\
\bar{Q}_{12} & \bar{Q}_{22}
\end{array}\right]_{k}\left[\begin{array}{ll}
a_{11} & a_{12} \\
a_{12} & a_{22}
\end{array}\right]\left[\begin{array}{c}
1 \\
0.5
\end{array}\right] p r
$$

Calculate lamina stresses in LT directions

$$
\left[\begin{array}{c}
\sigma_{\mathrm{L}, \mathrm{k}} \\
\sigma_{\mathrm{T}, \mathrm{k}}
\end{array}\right]=\left[\begin{array}{cc}
c^{2} & s^{2} \\
-s^{2} & c^{2}
\end{array}\right]_{k}\left[\begin{array}{l}
\sigma_{\mathrm{x}, \mathrm{k}} \\
\sigma_{\mathrm{y}, \mathrm{k}}
\end{array}\right] \quad, \quad \tau_{\mathrm{LT}, \mathrm{k}}=\left[\begin{array}{ll}
-s c & s c
\end{array}\right]\left[\begin{array}{l}
\sigma_{\mathrm{x}, \mathrm{k}} \\
\sigma_{\mathrm{x}, \mathrm{k}}
\end{array}\right]
$$

\section{Strength in layer $\mathbf{k}$}

Strength in L direction is related to volume fractions of fibres

$$
\frac{E_{\mathrm{L}}}{E_{\mathrm{T}}}=p \approx \frac{V_{\mathrm{fL}}}{V_{\mathrm{fT}}} \rightarrow V_{\mathrm{fT}}=\frac{1}{p} V_{\mathrm{fL}} \quad, \quad V_{\mathrm{fL}}+V_{\mathrm{fT}}=V_{\mathrm{f}}^{0}
$$

Total average volume fraction of fibres if conserved and divided to $\mathrm{L}$ and $\mathrm{T}$ directions 


$$
V_{\mathrm{f}}^{0}+V_{\mathrm{m}}{ }^{0}=1, V_{\mathrm{fL}}+V_{\mathrm{mL}}=1, \quad V_{\mathrm{fT}}+V_{\mathrm{mT}}=1
$$

Volume fraction portions for $\mathrm{L}$ and $\mathrm{T}$ directions are

\section{Strength formulas}

$$
V_{\mathrm{fL}}=\frac{p}{1+p} V_{\mathrm{f}}^{0} \quad, \quad V_{\mathrm{fT}}=\frac{1}{p} V_{\mathrm{fL}}=V_{\mathrm{mL}}
$$

Strength depends on length of fibres and mechanism of strengthening If $\mathbf{s}>\mathbf{s}_{\mathbf{c}}$ then the overcritical strength formula applies

$$
\sigma_{\mathrm{LU}}=\sigma_{\mathrm{fu}} V_{\mathrm{fL}}+\sigma_{\mathrm{m} \varepsilon_{\mathrm{f}}} * V_{\mathrm{mL}}, \quad \sigma_{\mathrm{TU}}=\sigma_{\mathrm{fu}} V_{\mathrm{fT}}+\sigma_{\mathrm{m} \varepsilon_{\mathrm{f}}} * V_{\mathrm{mT}}, \tau_{\mathrm{LTU}}=83
$$

Else if $\mathbf{s}<\mathbf{s c}$, then undercritical then strength formula applies

It is assumed $m=1$ meaning full slipping

$$
\begin{gathered}
\sigma_{\mathrm{LU}}=2 m s \tau_{\mathrm{i}} \cdot(1-1 / 2 m) \bullet V_{\mathrm{fL}}+\sigma_{\mathrm{m} \varepsilon_{\mathrm{f}}} * V_{\mathrm{mL}} \\
\sigma_{\mathrm{TU}}=2 m s \tau_{\mathrm{i}} \cdot(1-1 / 2 m) \bullet V_{\mathrm{fT}}+\sigma_{\mathrm{m} \varepsilon_{\mathrm{f}}} V_{\mathrm{mT}} \rightarrow s<s_{\mathrm{c}}
\end{gathered}
$$

End if condition $s<>s_{c}$

\section{Failure criterion $\boldsymbol{F}_{\mathrm{k}}$ for each layer $\mathrm{k}$}

Now failure criteria for each layer $\mathrm{k}$, fibre material $\mathrm{Im}$, aspect ratio $s$ and environmental loadings are obtained

For $\mathrm{k}=1$ to 4 , get $F(\mathrm{k})$

$$
F_{\mathrm{k}}\left(\theta_{\mathrm{k}}\right)=\left(\frac{\sigma_{\mathrm{L}}}{\sigma_{\mathrm{LU}}}\right)_{\mathrm{k}}^{2}-\left(\frac{\sigma_{\mathrm{L}}}{\sigma_{\mathrm{LU}}}\right)_{k}\left(\frac{\sigma_{\mathrm{T}}}{\sigma_{\mathrm{TU}}}\right)_{k}+\left(\frac{\sigma_{\mathrm{T}}}{\sigma_{\mathrm{TU}}}\right)_{\mathrm{k}}^{2}+\left(\frac{\tau_{\mathrm{LT}}}{\tau_{\mathrm{LTU}}}\right)_{\mathrm{k}}^{2} \leq 1
$$

\section{Next k}

5. Next k, for each lamina stresses and strengths and failure criteria

4. Next Ith, Angle $\theta$ (Ith) is varied

3. Next Iss, $\quad \mathrm{s}=5000,20,1$, aspect ratio is decreased if environmental attack by stress corrosion cuts fibres

2. Next IVf, $\quad V_{\mathrm{f}}=0.14$ to 0.46 is lower at inner and higher for support layer 1. Next Itt, wall thickness
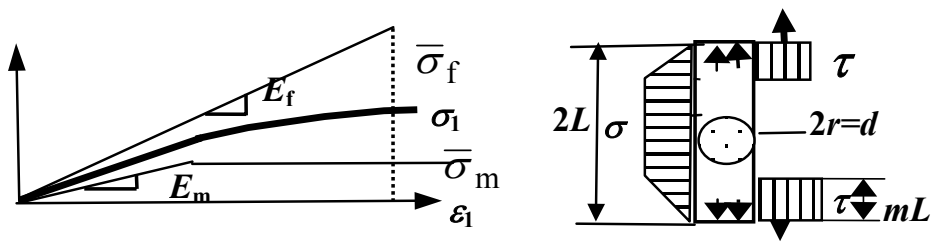

Figure 5: $\quad$ Basic models of laminate and fibre strength behaviour.

\subsection{Goals and results}

The main goal is minimisation of cost subject to desired values of failure criteria of layers. The cost is related to thickness times cost of a unit mass. The second 
goal is to constrain product of failure criterions. The third goal is to obtain stress corrosion life of fibres sufficiently large by fibre and matrix material selections.

A. At new materials, interfacial matrix strength is $\tau_{\mathrm{i}}=83 \mathrm{MPa}, \mathrm{LT}$ strengths are $\sigma_{\mathrm{LUk}}=320, \sigma_{\mathrm{TUk}}=125$. When long fibres $s=5000$, failure $F=0.073$. Strains $\varepsilon_{\mathrm{x}}=0.0015, \varepsilon_{\mathrm{y}}=0.0028$ are close to allowed strain 0.0015 .

B. Next matrix degradation is assumed from $\tau_{\mathrm{i}}=83$ to 40 causing $F$ rise to 0.1

C. If cracking decreases aspect ratio to $s=20$, with lowing of matrix strength to $\tau_{\mathrm{i}}=40$, then $F$ increases further but not much to 0.11 .

D. If cracking of fibres is maximal, then aspect ratio is minimal, $s=1$. If also matrix is degraded to $\tau_{\mathrm{i}}=40$, then $\sigma_{\mathrm{LUk}}=40$ and $\sigma_{\mathrm{TUk}}=40$. Failure criteria are large predicting full failure $F>4$. Also strains are large $\varepsilon_{\mathrm{x}}=0.004, \varepsilon_{\mathrm{y}}=0.01$.

E. Stress corrosion cracking life at pressure $1 \mathrm{MPa}$ gave hoop stress 45 . At $1 \mathrm{~N}$ $\mathrm{H}_{2} \mathrm{SO}_{4}$ acid load reasonable threshold stress intensity is $K_{\mathrm{Ii}}=5$ for typical E-glass giving 0.02 years. Somewhat more chemically resistant E-glass with $K_{\mathrm{Ii}}=1$ may give 0.1 years. Most optimal is to use such fibres which endure these acids well.

\section{Microscopy characterisation}

Scanning electron microscopy was applied to study the microstructure of a sample of thickness $9 \mathrm{~mm}$ which had been 2 years in saturated acid vapour gas, Figure 6 . Then it had been tested to fracture in three point bending test.

During the 2 years of acid attack the stress was low. At the final test it was applied up to fracture load. Evidently fibres had been weakened substantially as shown by its lowered strength value. Also little sign of matrix was found.
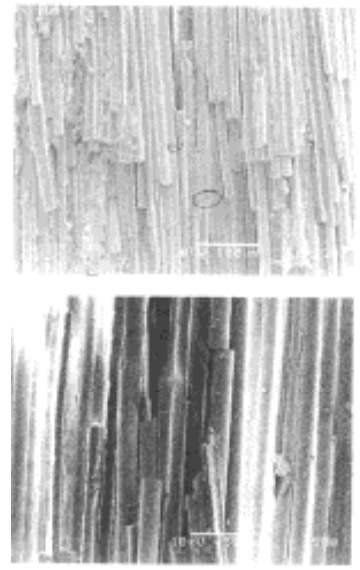
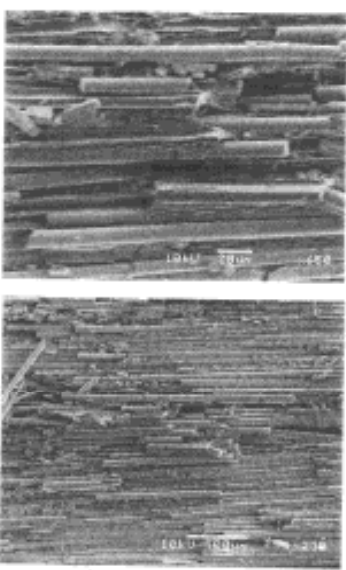
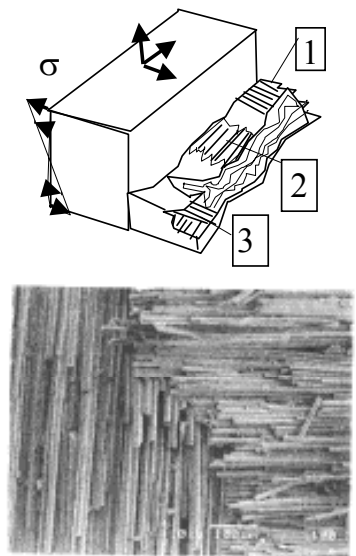

Figure 6: $\quad$ SEM characterisation. Location (1) is at neutral surface and fracture mode is mainly shearing and fibre tensile fractures, at left up (230x) and left down (500x). Location (2), (at middle top 650x and top down 230x) shows fibres at transverse direction. c) Right down (at $180 \mathrm{x}$ ) at location (3) close to the tensile surface shows axial and transverse fibre fractures but little matrix left. 


\section{Optimisation of pipe manufacturing and structure}

An industrial pipe made of continuous fibre and mat as sketched in Figure 2. Diameter is $2 \mathrm{~m}$ and load is internal pressure of $1 \mathrm{MPa}$. Volume fraction is 0.46 , moduli and Poisson's ratios: $E_{\mathrm{f}}=72000 \mathrm{MPa}, v_{\mathrm{f}}=0.22, E_{\mathrm{m}}=3450, v_{\mathrm{m}}=0.38$, densities $\rho_{\mathrm{f}}=2590 \mathrm{~kg} / \mathrm{m}^{3}, \rho_{\mathrm{m}}=1200$. Individual ply lamina LT properties were $E_{\mathrm{L}}=35300, E_{\mathrm{T}}=6150, G_{\mathrm{LT}}=2244, v_{\mathrm{LT}}=0.3, v_{\mathrm{TL}}=0.053$. Allowable strains of 0.0015 were achieved. Two manufacturing methods are competing options:

A. Manufacturing with 90/0deg winding can be done with a simple machine and control but requires costly axial mats. This gives pipes with about $30 \%$ fibres in hoop and $70 \%$ in axial direction.

B. Manufacturing with $60 \mathrm{deg}$ gives equal strains to the hoop and axial directions but requires a programmable costlier machine. Advantages are that low cost continuous roving can be used.

\section{Conclusions}

The following conclusions can be drawn.

- In this study the results are presented of designing optimally industrial large vessel shell microstructures made of fibre reinforced plastic laminates and subject to mechanical and aggressive acids at high temperatures.

- Optimal performance microstructure is obtained by use of balanced and symmetric laminate layering with optimal fibre directions and chemically resistant fibres and matrix. Thicker wall is cost-effective for vessel bottoms.

- Industrial end-users require pipes to have same allowed strains in main directions. Manufacturing choices determine also microstructures: the 90/0deg winding requires simple machine but costly mats, the $60 \mathrm{deg}$ winding requires complex machine but with inexpensive continuous roving.

\section{Acknowledgements}

The assistance in SEM analyses by Mr. Markku Levomäki, MSc, is gratefully acknowledged. This research is supported by EU Asia Link Project (Contract Reference no.: ASI/B7-301/98/679-023)

\section{References}

[1] Agarwal, B.D.and Broutman L.J.Analysis and performance of fiber composites, John Wiley \& Sons, Inc.1990.

[2] Barbero, E.J. Introduction to composite materials design, Taylor \& Francis, 1999.

[3] Aveston, J. and Sillwood, J.M. Long term strength of glass-reinforced plastics in dilute sulphuric acid. Journal of materials science 17 (1982) 3491-3498.

[4] Kawada, H. and Srivastava, V.K., The effect of an acidic stress environment on the stress-intensity factor for GRP laminates. Composites science and technology 61 (2001) 1109-1114. 